\title{
Entre el paraíso de la abundancia y el infierno del hambre: mitos y realidades
}

\author{
María de los Ángeles Pérez SAMPeR ${ }^{1}$ \\ Universidad de Barcelona \\ angelesperez@ub.edu
}

Fecha de recepción: 19/02/2015

Fecha de aceptación: 17/03/2015

\begin{abstract}
RESUMEN
Entre los sueños y la realidad, la tierra de Jauja, como Cucaña, era un país mágico insistentemente imaginado y buscado durante la Edad Moderna. En esta tierra fantástica no era necesario trabajar y el alimento era abundante. El mito surgió en una sociedad oprimida, que encontraba un alivio en estas fantasías, aunque muchos trataron de hacerlo realidad, buscándolo en otras tierras más allá del mar. América se convertiría en la proyección de esos sueños.
\end{abstract}

Palabras clave: Alimentación, abundancia, hambre, mito, imaginario, España, América, edad moderna

\section{Between the Paradise of Plenty and Hell of Hunger: Myths and Realities}

\begin{abstract}
Between dreams and reality, the land of Cockaigne was a magical country repeatedly imagined and sought for the Early Modern Age. In this fantastic land was not necessary to work and food was plentiful. The myth arose in an oppressed society, which was a relief in these fantasies, though many tried to make it happen, searching in other lands beyond the sea. America became the projection of those dreams.
\end{abstract}

Key words: Power, Wealth, Hunger, Myth, Imagination, Spain, America, Early Modern Age.

1 Este trabajo se ha realizado en el marco del Proyecto CICYT. Convocatoria 2011. Ministerio de Economía y Competitividad. Referencia: HAR2011-26435-C03-02. Título del proyecto: "El hecho cotidiano en la Monarquía Española de la Edad Moderna: Cataluña y Barcelona". Y en el marco del "Grup de recerca consolidat" (AQU. Generalitat de Catalunya), Referencia 2014 SGR 173. Grup d'Estudis d'Història del Mediterrani Occidental. Societat, poder i cultura a l'època moderna (Universidad de Barcelona). 


\section{MITOS DE HARTURA}

Entre las más famosas utopías medievales se encuentra la de un país maravilloso, el país de Cucaña, en el que se vive sin trabajar y donde la comida, la más deseada, se ofrece generosamente. El país de la Cucaña es la variante laica de la búsqueda y localización del paraíso terrenal, asociado a lo alimenticio y destinado a los glotones. Es un lugar en donde pagan por descansar y castigan por trabajar; los árboles son de buñuelos, las casas están hechas de pasteles, hay ríos de leche y animales ya cocinados que deambulan dispuestos a ser engullidos. A éstos se asocian otros motivos como la presencia de oro, la fuente de la juventud y el placer carnal. Todos deseaban encontrar ese país y en la literatura eran numerosos los viajes imaginarios en que gentes hambrientas y desesperadas se aventuraban por mares ignotos para lograr alcanzar la deseada abundancia ${ }^{2}$.

El tema del contraste entre la abundancia y la escasez en la alimentación fue tratado desde múltiples perspectivas. Caso notable es el de Juan Ruiz, conocido como el Arcipreste de Hita, creador de una de las obras más importantes de la literatura medieval española, el Libro de buen amor ${ }^{3} \mathrm{El}$ tema no es una tierra legendaria, es una batalla. En la pelea de Don Carnal con Doña Cuaresma se manifiestan claramente los dos imaginarios, el del hambre, Doña Cuaresma, y el de la abundancia, Don Carnal, en este caso con claras referencias religiosas a la división entre los días de carne y los días de pescado, derivada de los preceptos eclesiásticos del ayuno y la abstinencia, que obligaban especialmente en Cuaresma, también todos los viernes a lo largo del año y las vigilias de las grandes fiestas litúrgicas. Nada mejor que el Carnaval, fiesta de subversión y de inversión, para denunciar la desigualdad en el tema de la alimentación, necesidad vital de todos los seres humanos en todas las épocas y en todos los lugares, cuya satisfacción estaba, sin embargo, tan mal cubierta y tan mal distribuida, pues mientras unos pocos comían mucho y bien, la gran mayoría comía poco y mal, y eran muchos los que pasaban hambre e incluso morían de ella.

Las huestes de Don Carnal las constituyen carnes de todas clases, los alimentos más apreciados de la época, considerados propios de nobles, ricos y poderosos, con algunos añadidos de queso y vino:

... gallinas, e perdiçes, conejos, e capones, ánades, e lavancos, e gordos ansarones, las ánsares, çeçinas, costados de carneros, piernas de puerco fresco, los jamones en-

2 LE GOFF, J.: "Le pays de Cocagne", Revue européenne des sciences sociales, XXVII, 85 (1989). Lumières, utopies, révolutions: espérance de la démocratie: à Bronislaw Baczko, Ginebra, Droz, 1989, pp. 271-286. LE GOFF, J.: "Cocagne", en Héros et merveilles du Moyen Âge, Paris, Seuil, 2005, p. 110-119. DELUMEAU, J. (dir.): La Mort des pays de Cocagne: comportements collectifs de la Renaissance à l'âge classique, Paris, Université, 1976. DEMERSON, G. "Cocagne, utopie populaire?", Revue belge de philologie et d'histoire, t. 59, fasc. 3, (1981), pp. 529-553. Franco JúnIOR, H., Cocagne: histoire d'un pays imaginaire, Paris, Ed. Arkhê, 2013. Payen, J.-Ch.: "Fabliaux et Cocagne: abondance et fête charnelle dans les contes plaisants du XII et du XIII ${ }^{\mathrm{e}}$ siècles", en BIANCIOTTO, G. y SALVAT, M. (ed.): Épopée, fable, fabliau. Actes du IVE colloque de la Société internationale renardienne, Évreux, 7-11 septembre 1981, Paris, Presses universitaires de France, Publications de l'Université de Rouen, 83, Cahiers d'études médiévales, 2/3, (1984), pp. 435-448.

3 RUIZ, J., Arcipreste de Hita: Libro de buen amor. Ed. crítica de Alberto Blecua. Madrid: Cátedra, 1992. 
teros, las puestas de la vaca, lechones et cabritos, muchos quesuelos fritos, los vinos bien tintos, muchos buenos faysanes, los loçanos pavones, muchos gamos, e el fuerte jabalí, muy ligero el çiervo, la liebre, el cabrón montés con corços e torcasas, el buey, don Toçino con mucha otra çeçina...

Las mesnadas de Doña Cuaresma están formadas de los alimentos de los días de abstinencia en que está prohibida la carne, sustancialmente pescados y alguna hortaliza, entonces todo ello poco apreciado y considerado alimento de gentes pobres:

... el puerro cuello albo, la salada sardina, las grandes mielgas, los berdeles e gibias, de parte de Valençia veníen las anguilas, salpresas e trechadas a grandes manadillas, el atún, de parte de Bayona veníen muchos caçones, del río de Enares venían los camarones, barvos et peçes, la pixota, la lija, de Sant Ander vinieron las bermejas langostas, arenques et besugos vinieron de Bermeo, las sabogas, el delfín, sábalos et albures et la noble lamprea de Sevilla et de Alcántara venían, el sollo, el pulpo, las ostras, los ásperos cangrejos, congrio, çeçial e fresco, don Salmón de Castro de Urdiales, la gigante ballena...

En Carnaval el mito de la carne se ensalza y se proclama. Se trataba de comer mucho, de comer carne, especialmente carne de cerdo. Carnaval significaba precisamente el adiós a la carne, en vísperas de la Cuaresma, tiempo de penitencia, tiempo de ayuno, de comer poco, y de abstinencia de carne. Nada mejor que una espléndida despedida a la carne, que no solo marcaba el contraste con la Cuaresma, sino el permanente contraste entre comer mucho y bien y comer poco y mal, en que la sociedad se dividía y se debatía.

El tema continuó en la edad moderna. Muy significativo es el cuadro titulado El combate entre don carnaval y doña cuaresma, obra del pintor flamenco Pieter Brueghel el Viejo, pintado en el año 1559 (Kunsthistorisches Museum, Gemäldegalerie, Viena). La idea está tomada de un tema típico de la literatura de la época y su objetivo es presentar el contraste entre dos aspectos de la vida, la abundancia y la privación, el placer y la mortificación, así la presencia de una posada en el lado izquierdo, para el goce, y la iglesia a la derecha, para la devoción. Se parodia, por un lado, a los que celebran el carnaval y, por otro, a los devotos que cumplen con la cuaresma.

Don Carnal está representado por el hombre gordo y orondo, que cabalga encima de un barril de cerveza, que lleva por sombrero un pastel y en vez de una lanza, blande un espetón en el que se hallan ensartados una cabeza de cerdo, un pollo, varias salchichas. Combate Don Carnal contra Doña Cuaresma, simbolizada por la demacrada mujer que se sienta sobre un reclinatorio, del que tiran un monje y una monja; lleva por sombrero una colmena, y porta una pala con dos arenques, señalando la abstinencia de carne y el recurso al pescado. Al lado, una olla con mejillones, y esparcidos alrededor "pretzels" y galletas.

Montones de personajes, de toda clase y condición, escenas varias, una mujer cocinando una especie de crêpes o filloas, otra mujer vendiendo pescado, hombres bebiendo junto a grandes barriles de cerveza, al fondo una panadería, gentes bailando y jugando a los dados, otros pidiendo limosna. El contraste entre dos mundos y dos tiempos, el tiempo de la carne y el tiempo de la prohibición de la carne, como sím- 
bolo de una sociedad escindida entre dos bloques, el de comer mucho y bien y el de comer poco y mal. Todos querían escapar del mundo del hambre y pasar al mundo de la abundancia. Había que buscar el camino para encontrar ese mundo de abundancia.

\section{EL DESCUBRIMIENTO DEL PARAÍSO}

Hubo muchos lugares imaginarios, pero hubo un lugar maravilloso que fue absolutamente real. Desde el primer momento en que Cristóbal Colón descubrió América tuvo el convencimiento de que había llegado al Paraíso. A medida que fue recorriendo las islas más maravilloso le pareció aquel Nuevo Mundo, donde la naturaleza era extraordinaria y parecía ofrecerlo todo por nada.

El Diario de viaje del Almirante en aquel año de 1492 resulta bien expresivo de esa emoción que le embargaba ante una realidad tan hermosa. Los primeros días en las nuevas tierras eran de continua admiración ${ }^{4}$. El 13 de octubre decía: "Esta isla es bien grande y muy llana y de árboles muy verdes y muchas aguas y una laguna en medio muy grande, sin ninguna montaña, y toda ella verde, que es placer de mirarla"5. El 14 de octubre: "Y después junto con la dicha isleta están huertas de árboles las más hermosas que yo vi, y tan verdes y con sus hojas como las de Castilla en el mes de abril y de mayo, y mucha agua" ${ }^{6}$. El 15 de octubre: "Son estas islas muy verdes y fértiles y de aires muy dulces, y puede haber muchas cosas que yo no sé, porque no me quiero detener por calar y andar muchas islas para hallar oro" 7 .

Cada isla que descubrían era una nueva sorpresa, por su hermosura y por su novedad, todo tan distinto a lo que conocían en España. El 16 de octubre:

Es isla muy verde y llana y fertilísima, y no pongo duda de que todo el año siembran panizo y cogen, y así todas otras cosas. Y vi muchos árboles muy disformes de los nuestros, y de ellos muchos que tenían los ramos de muchas maneras y todo en un pie, $\mathrm{y}$ un ramito es de una manera y otro de otra, $\mathrm{y}$ tan disforme que es la mayor maravilla del mundo cuánta es la diversidad de una manera a la otra ${ }^{8}$.

Enorme admiración les suscitó "la isla grande", la isla más grande del archipiélago de las Islas Galápagos, a la que Colón denominó Isabela, en honor de la Reina Isabel. El 19 de octubre:

... la isla grande; (...) a la cual puse nombre de la Isabela. El viento era Norte, y quedaba el dicho isleo en derrota de la isla Fernandina, de adonde yo había partido [...] Esta costa toda y la parte de la isla que yo vi es toda casi playa, y la isla más hermosa cosa que yo vi; que si las otras son muy hermosas, ésta es más. Es de muchos árboles

\footnotetext{
4 COLÓN, C.: Los cuatro viajes del almirante y su testamento, edición y prólogo de Ignacio B. Anzoátegui, Alicante, Biblioteca Virtual Miguel de Cervantes, 2002, Edición digital basada en la 10 a ed. de Madrid, Espasa-Calpe, 1991.

5 Ibidem, p. 32.

6 Ibidem, p. 33.

7 Ibidem, p. 36.

8 Ibidem, pp. 37-38.
} 
y muy verdes y muy grandes, y esta tierra es más alta que las otras islas halladas, y en ella algún altillo, no que se le pueda llamar montaña, mas cosa que hermosea lo otro, y parece de muchas aguas allá al medio de la isla. (...) Hay muchos arboledos y muy espesos y muy grandes. Yo quise ir a surgir en ella para salir a tierra y ver tanta hermosura; (...) y el viento era muy bueno para venir a este cabo adonde yo surgí ahora, al cual puse nombre Cabo Hermoso, $[\ldots]$ porque vi este cabo de allá tan verde y tan hermoso, así como todas las otras cosas y tierras de estas islas que yo no sé adónde me vaya primero ni me sé cansar los ojos de ver tan hermosas verduras y tan diversas de las nuestras. Y aun creo que hay en ella muchas hierbas y muchos árboles que valen mucho en España para tinturas y medicinas de especiería, mas yo no los conozco, de que llevo grande pena. Y llegando yo aquí a este cabo vino el olor tan bueno y suave de flores o árboles de la tierra, que era la cosa más dulce del mundo 9 .

Día a día, cada isla que descubrían no hacía sino aumentar su admiración. 21 de octubre:

... me salí con estos capitanes y gente a ver la isla; que si las otras ya vistas son muy hermosas y verdes y fértiles, ésta es mucho más y de grandes arboledos y muy verdes. Aquí es unas grandes lagunas, y sobre ellas y a la rueda es el arboledo en maravilla, y aquí y en toda la isla son todos verdes y las hierbas como en abril en el Andalucía; y el cantar de los pajaritos que parece que el hombre nunca se querría partir de aquí, y las manadas de los papagayos que oscurecen el sol; y aves y pajaritos de tantas maneras y tan diversas de las nuestras que es maravilla; y después hay árboles de mil maneras y todos de su manera fruto, y todos huelen que es maravilla, que yo estoy el más apenado del mundo de no conocerlos, porque soy bien cierto que todos son cosa de valía, y de ellos traigo la muestra y asimismo de las hierbas ${ }^{10}$.

La impresión de haber hallado la tierra de las maravillas se repite. Día a día se anotaban nuevos elogios. 28 de octubre:

Fue de allí en demanda de la isla de Cuba al Sursudoeste, a la tierra de ella más cercana, y entró en un río muy hermoso (...) Dice el Almirante que nunca tan hermosa cosa vio, lleno de árboles, todo cercado el río, hermosos y verdes y diversos de los nuestros, con flores y con su fruto, cada uno de su manera. Aves muchas y pajaritos que cantaban muy dulcemente; había gran cantidad de palmas de otra manera que las de Guinea y de las nuestras, de una estatura mediana y los pies sin aquella camisa y las hojas muy grandes, con las cuales cobijan las casas; la tierra muy llana. [...] La hierba era grande como en el Andalucía por abril y mayo. Halló verdolagas muchas y bledos. Tornóse a la barca y anduvo por el río arriba un buen rato, y dice que era gran placer ver aquellas verduras y arboledas, y de las aves que no podía dejarlas para se volver. Dice que es aquella isla la más hermosa que ojos hayan visto, llena de muy buenos puertos y ríos hondos, y la mar que parecía que nunca se debía de alzar porque la hierba de la playa llegaba hasta casi el agua, la cual no suele llegar donde la mar es brava ${ }^{11}$.

\footnotetext{
9 Ibidem, p. 41.

10 Ibidem, p. 43.

11 Ibidem, pp. 47-48.
} 
La belleza de las islas, la abundancia de agua, la fertilidad de la tierra, el verde de la vegetación, eran los temas recurrentes en las anotaciones del diario, aquello que más les sorprendía y admiraba. 3 de noviembre:

En la mañana entró en la barca el Almirante, y porque hace el río en la boca un gran lago, (...) entró por el río arriba hasta llegar al agua dulce, que sería cerca de dos leguas, y subió en un montecillo por descubrir algo de la tierra, y no pudo ver nada por las grandes arboledas, las cuales eran muy frescas, odoríferas, por lo cual dicen no tener duda que no haya hierbas aromáticas. Dice que todo era tan hermoso lo que veía, que no podía cansar los ojos de ver tanta lindeza y los cantos de las aves y pajaritos ${ }^{12}$.

Maravillados de todo lo que veían, destacaban la novedad, tratando de compararlo con lo existente en España. El 4 de noviembre anotaban en el diario:

Estas tierras son muy fértiles: ellos las tienen llenas de mames, que son como zanahorias, que tienen sabor de castañas, y tienen faxones y habas muy diversas de las nuestras y mucho algodón, el cual no siembran, y nacen por los montes árboles grandes, y creo que en todo tiempo lo hay para coger, porque vi los cogujos abiertos y otros que se abrían y flores todo en un árbol, y otras mil maneras de frutas que me no es posible escribir; y todo debe ser cosa provechosa ${ }^{13}$.

Plantas, animales, todo les parecía admirable. 6 de noviembre:

Vieron muchas maneras de árboles e hierbas y flores odoríferas. Vieron aves de muchas maneras diversas de las de España, salvo perdices y ruiseñores que cantaban y ánsares, y de esto hay allí harto; bestias de cuatro pies no vieron, salvo perros que no ladraban. La tierra muy fértil y muy labrada de aquellos mames y faxoes y habas muy diversas de las nuestras; eso mismo panizo y mucha cantidad de algodón [...] Dice el Almirante que le parecía que no lo sembraban y que da fruto todo el año ${ }^{14}$.

En los nombres que Colón daba a los nuevos lugares se refleja por un lado el mundo de los sueños y por otro el mundo de la realidad, a un valle se le da el nombre del Paraíso, a un río el nombre de Guadalquivir, por una parte la utopía, por otra parte la nostalgia de lo propio. 15 de diciembre: "Vio algunas cosas y el valle grande donde están las poblaciones, y dijo que otra cosa más hermosa no había visto. [...] Puso nombre al valle Valle del Paraíso, y al río Guadalquivir, porque dice que así viene tan grande como el Guadalquivir por Córdoba..." 15

La conclusión de todo ese proceso de sorpresa y de maravilla era naturalmente identificar aquel Nuevo Mundo con el Paraíso. El Diario de viaje es un claro testimonio de ese firme convencimiento de Cristóbal Colón. 21 de febrero de 1493:

\footnotetext{
12 Ibidem, p. 53.

13 Ibidem, p. 54.

14 Ibidem, p. 56.

15 Ibidem, pp. 89-90.
} 
Partió ayer de aquella isla de Santa María para la de San Miguel, para ver si hallaba puerto para poder sufrir tan mal tiempo como hacía, con mucho viento y mucha mar. [...] Dice que estaba maravillado de tan mal tiempo como había en aquellas islas y partes, porque en las Indias navegó todo aquel invierno sin surgir, y había siempre buenos tiempos, y que una sola hora no vio la mar que no se pudiese bien navegar, y en aquellas islas había padecido tan grave tormenta, y lo mismo le acaeció a la ida hasta las Islas de Canaria; pero, pasado de ellas, siempre halló los aires y la mar con gran templanza. Concluyendo, dice el Almirante que bien dijeron los sacros teólogos y los sabios filósofos que el Paraíso Terrenal está en el fin de Oriente, porque es lugar temperadísimo. Así que aquellas tierras que ahora él había descubierto es -dice él- el fin del Oriente ${ }^{16}$.

\section{LOCOS Y LOCURAS}

De locos se podría tachar a Colón y a sus hombres, lanzados mar adentro en busca del paraíso. Tuvieron suerte y lo hallaron. En esos mismos años, mientras unos encontraban un verdadero paraíso en el Nuevo Mundo, otros en el Viejo Mundo continuaban soñando con él. El país de Jauja era una tierra de riquezas que aparece como destino de la nave de los necios en la obra de Sebastián Brant, Das Narrenschiff (Basilea, 1494) ${ }^{17}$. "¡Vosotros, compañeros, venid aquí en seguida! Vamos al País de las Maravillas". El libro de Brant resulta muy evocador de esa búsqueda desesperada del paraíso.

Algunas de sus ilustraciones proporcionan curiosas imágenes del imaginario de la glotonería. 2. Dos necios tratan de meter un cerdo en un caldero. Al que está agachado se le hace la boca agua. 14. En un establo, comen gansos y cerdas. Un necio, con una gran cuchara en la mano y una lata en torno al cuello, los mira. 16. Se representa un festín. Un necio bebe de una jarra, otro hinca el diente a un jamón, otros levantan los vasos en señal de brindis. 60 . Un viejo necio se mira al espejo mientras remueve la comida de una olla. Junto al fogón y los utensilios de cocina aparece una oveja. 81. La escena representa una cocina al aire libre junto a una playa. Un necio sujeta desde una barca a cinco personajes: una mujer, en primer plano, cuida el fuego y asa un pollo; un hombre lleva mandil y llaves, parece el encargado de la bodega; otro es un cocinero, que está removiendo en una sartén; otro bebe de un cántaro; el quinto ha cogido pícaramente carne con una larga vara.

El libro de Brant inspiró a El Bosco para su Nave de los locos. Como el resto de obras de su autor, carece de una datación unánime entre los especialistas. Unos han señalado el período 1503-1504, mientras que otros indican, simplemente, después de 1490. Describe la locura de la humanidad viciosa y pecadora y muestra a gentes que malgastan sus vidas, comiendo, bebiendo, flirteando, jugando a las cartas, en lugar vivir de manera responsable y piadosa. A través de la pintura se critican las costumbres de la sociedad de la época. La barca donde se come, se bebe y se canta, va a la deriva. Representa la gula y la lujuria, evocadas con detalles como el ave asada ensartada

\footnotetext{
16 Ibidem, p. 146-147.

17 BRANT, S.: La nave de los necios, Madrid, Akal, 1998.
} 
en el árbol que sirve de mástil a la nave y que un hombre trata con dificultades de alcanzar, la bota de vino y el plato de cerezas.

El gran humanista Erasmo de Rotterdam en su Elogio de la locura (Enchomion moriae seu laus stultitiae), de 1511, también trataba el tema de la tierra de la abundancia. El personaje protagonista, la locura, confiesa ser natural de la tierra de Jauja: "Diré que no provengo de la errática Delos, ni del undoso mar, ni de las profundas cavernas, sino de las mismas islas Afortunadas, donde todo crece espontáneamente y $\sin$ labor" ${ }^{18}$. Erasmo ironiza sobre la sabiduría. Frente al concepto establecido, pone la verdadera sabiduría en saber vivir la vida: “¿Qué sería, pues, esta vida, si vida pudiese entonces llamarse, cuando quitaseis de ella el placer?" 19

Planteaba a su manera el contraste entre los dos mundos, el de la privación y el de la abundancia:

¿No veis acaso a estos hombres severos dedicados a estudios de filosofía, o a graves $\mathrm{y}$ arduos asuntos, que han envejecido antes de llegar a la plena juventud, por obra de las preocupaciones y la constante y agria agitación de las ideas, que agota el espíritu y la savia vital? Por el contrario, mis necios están regordetes, lucidos, con piel brillante, a modo, según dicen, «de cerdos acarnanienses» ${ }^{20}$.

Y recurre al simbolismo mitológico, al combate entre Baco, el dios del placer, y Palas Atenea, la diosa del saber: “¿Por qué Baco ha sido siempre efebo y le ha adornado poblada cabellera? Porque, insensato y borracho, se ha pasado la vida entera en banquetes, danzas, cantos y diversiones, sin tener nunca el menor trato con Palas" ${ }^{21}$.

Alude al placer de la comida, como el placer por excelencia, o como mínimo el más duradero. Elogia a la mesa como centro de la buena vida, donde no solo se come y se bebe, sino en la que pueden practicar muchos otros placeres y diversiones:

Pero algunos hay, y en primera fila los viejos, que son más bebedores que mujeriegos y sitúan la suma voluptuosidad en la mesa. Juzguen otros de si habrá banquete completo sin mujeres; lo que sí consta es que ninguno resulta agradable sin el condimento de la estulticia. (...) Porque, ¿a qué conduce cargar el vientre de toda clase de confituras, manjares y golosinas, si los ojos y los oídos, si no todo el ánimo, han de apacentarse también con risas, bromas y chistes? De esta manera, yo [la locura] soy artífice insustituible de las sobremesas, porque aquellas ceremonias de los banquetes, como elegir rey a suertes, jugar a los dados, los brindis recíprocos, el establecer rondas, cantar coronados de mirto, bailar y hacer pantomimas, no fueron inventadas por los siete sabios de Grecia, sino por mí, para bien del género humano ${ }^{22}$.

El país de Jauja también estaba descrito en el libro de Hans Sachs, Schlaraffenland, publicado en 1530. "Schlaraffenland" es la tierra de la abundancia, o también

\footnotetext{
18 ROTTERDAM, E. DE: Elogio de la locura, traducción, prólogo y notas de Pedro Voltes Bou, Alicante, Biblioteca Virtual Miguel de Cervantes, 1999, Madrid, Espasa Calpe, 1953. Capítulo VIII, p. 29.

19 Ibidem, Capítulo XII, p. 33.

20 Ibidem, Capítulo XIV, pp. 36-37.

21 Ibidem, Capítulo XV, p. 38.

22 Ibidem, Capítulo XVIII, ps. 43-44.
} 
"Luilekkerland", que significa "tierra de la glotonería". En ese país maravilloso los ríos no son de agua, sino de leche y miel, las fuentes de vino. Alimentos ya cocinados, cerdos, pollos, gansos, saltan y vuelan por todas partes, a disposición de quien alargue la mano y los coja para comer, sin tener que molestarse en ir a comprarlos y tener que prepararlos, incluso llevan cuchillos clavados, para facilitar la tarea de cortarlos. Los pescados nadan en el río ya cocidos o asados. Las casas están hechas de bizcocho y galleta, las vallas de salchichas, y las piedras son quesos. Todo es fácil y alegre, el trabajo duro es allí un pecado ${ }^{23}$.

\section{HAMBRE EN EL PARAÍSO}

Mientras unos escribían, leían, soñaban, otros se lanzaron a la acción. Los españoles que fueron a América, descubridores, conquistadores, colonizadores, fueron en busca de fama y fortuna. Estaban convencidos de ir al Paraíso, pero no todos lo encontraron. Buscaban la tierra de Jauja, donde la abundancia estaba asegurada, pero muchos encontraron justo lo contrario, una tierra de hambre, de un hambre terrible, mucho mayor que cualquiera de las otras hambres a las que muchos estaban ya acostumbrados en su propia tierra.

Uno de estos aventureros fue Alvar Núñez Cabeza de Vaca. Hombre de acción y escritor, participó en la expedición de Pánfilo de Narváez a la Florida. Fue uno de los 4 supervivientes de los 300 hombres que desembarcaron en Florida ${ }^{24}$. En su obra Naufragios $^{25}$ da un impresionante testimonio del hambre, su compañera inseparable en los largos años de aventuras y desventuras, de 1527 a 1536. Naufragios, considerada la primera narración histórica sobre los territorios que hoy corresponden a Estados Unidos, fue publicada en 1542 en Zamora y en 1555 en Valladolid.

De aquella odisea han quedado relatos escalofriantes del hambre terrible que padecieron y que provocó la muerte de muchos de aquellos hombres. Muy pronto se agotaron las provisiones y comenzaron los problemas: "hallamos gran cantidad de maíz que estaba ya para cogerse, y dimos infinitas gracias a nuestro Señor por habernos socorrido en tan grande necesidad, porque ciertamente, como éramos nuevos en los trabajos, allende del cansancio que traíamos, veníamos muy fatigados de hambre..."26

Camino de los Apalaches, empujados por el afán de encontrar el oro que buscaban, fueron muchas las penalidades padecidas:

... llegamos a vista de Apalache sin que los indios de la tierra nos sintiesen. Dimos muchas gracias a Dios por vernos tan cerca de Él, creyendo que era verdad lo que de aquella tierra nos habían dicho, que allí se acabarían los grandes trabajos que habíamos

23 RICHTER, D.: Schlaraffenland: Geschichte einer popularen Phantasie, Colonia, Dietrichs, 1984.

24 MAURA, J. F.: Alvar Núnez Cabeza de Vaca: el gran burlador de América, Valencia, Universidad de Valencia, 2008.

25 NÚÑEZ CABEZA DE VACA, Á.: Naufragios, Alicante, Biblioteca Virtual Miguel de Cervantes, 2003. Edición de Valladolid, [s.n.], 1555.

26 Ibidem. Capítulo V. Cómo dejó los navíos el gobernador. 
pasado, así por el malo y largo camino para andar, como por la mucha hambre que habíamos padecido; porque aunque algunas veces hallábamos maíz, las más andábamos siete y ocho leguas sin toparlo; y muchos había entre nosotros que, allende del mucho cansancio y hambre, llevaban hechas llagas en las espaldas, de llevar las armas a cuestas, sin otras cosas que se ofrecían. Mas con vernos llegados donde deseábamos, y donde tanto mantenimiento y oro nos habían dicho que había, pareciónos que se nos había quitado gran parte del trabajo y cansancio ${ }^{27}$.

Oro poco, hambre mucha. Peor que los ataques de los indios, era el cansancio y el hambre, comían lo que podían y al final recurrieron a comerse los caballos, a pesar de ser animales muy útiles, verdaderas armas de guerra, pero al no poder mantenerlos, mejor era convertirlos en su mantenimiento: “... anduvimos doscientas y ochenta leguas, poco más o menos. (...) y antes que nos embarcásemos, sin los que los indios nos mataron, se murieron más de cuarenta hombres de enfermedad y hambre. A veinte y dos días del mes de septiembre se acabaron de comer los caballos, que sólo uno quedó..." 28 . El hambre y la sed eran su compañía permanente: "tornamos a caminar por luengo de costa de vía del río de Palmas, creciendo cada día la sed y la hambre, porque los bastimentos eran muy pocos" 29 . Por mar o por tierra, el hambre era continua:

... navegamos cuatro días en compañía, comiendo por tasa cada día medio puño de maíz crudo. (...) y tantos días que padecíamos hambre, con los golpes que de la mar habíamos recibido, otro día la gente comenzó mucho a desmayar, de tal manera, que cuando el sol se puso, todos los que en mi barca venían estaban caídos en ella unos sobre otros, tan cerca de la muerte, que pocos había que tuviesen sentido... ${ }^{30}$

Era un hambre igualitaria. Todos pasaban hambre, los españoles y los indios. Y era un hambre extrema, aunque les esperaba padecerla todavía mayor: "Fue tan extremada la hambre que allí se pasó, que muchas veces estuve tres días sin comer ninguna cosa, y ellos [los indios] también lo estaban y parecíame ser cosa imposible durar la vida, aunque en otras mayores hambres y necesidades me vi después..." 31 . El riesgo de muerte fue constante en aquellos largos años para Alvar Núñez Cabeza de Vaca y sus compañeros: "Los trabajos que en esto pasé sería largo de contarlos, así de peligros y hambres, como de tempestades y fríos, que muchos de ellos me tomaron en el campo y solo, donde por gran misericordia de Dios nuestro Señor escapé" 32 . Hambre hasta más allá de lo soportable, hambre hasta la muerte. Fueron muchos los expedicionarios que murieron de hambre y los que sobrevivieron tuvieron que comerse los cadáveres de los que habían muerto:

\footnotetext{
27 Ibidem.

28 Ibidem. Cap. VIII. Cómo partimos de Aute.

29 Ibidem. Cap. IX. Cómo partimos de bahía de Caballos.

30 Ibidem. Cap. X. De la refriega que nos dieron los indios.

31 Ibidem. Cap. XV. De lo que nos acaeció en la isla de Mal Hado.

32 Ibidem. Cap. XVI. Cómo se partieron los cristianos de la isla de Mal Hado.
} 
... cuando allí llegaron ya se les habían muerto dos compañeros en sesenta leguas que habían andado; y que todos los que quedaban estaban para lo mismo, y que en todo el camino no habían comido sino cangrejos y yerba pedrera; (...) y los cristianos, viendo el tiempo que era, porque era por el mes de noviembre, pararon en este monte, porque hallaron agua y leña y algunos cangrejos y mariscos, donde de frío y de hambre se comenzaron poco a poco a morir. (...) y los que morían, los otros los hacían tasajos; y el último que murió fue Sotomayor, y Esquivel lo hizo tasajos, y comiendo de él se mantuvo hasta primero de marzo... ${ }^{33}$

Para remediar el hambre comían lo que encontraban. Aprendían de los indios a aprovechar algunos recursos, como las tunas, frutas de la planta de la tuna. Cuando no tenían otras cosas, las tunas se convertían en un manjar:

En todo el tiempo que comíamos las tunas teníamos sed, y para remedio de esto bebíamos el zumo de las tunas y sacábamoslo en un hoyo que en la tierra hacíamos, y desque estaba lleno bebíamos de él hasta que nos hartábamos. Es dulce y de color de arrope; esto hacen por falta de otras vasijas. Hay muchas maneras de tunas, y entre ellas hay algunas muy buenas, aunque a mí todas me parecían así, y nunca la hambre me dio espacio para escogerlas ni para mientes en cuáles eran las mejores ${ }^{34}$.

Si en el viaje pasaron muchas necesidades, no fue mejor el tiempo que los seis sobrevivientes vivieron entre indios, todos eran pueblos muy miserables, que también pasaban mucha hambre:

siempre fuimos bien tratados, aunque lo que habíamos de comer lo cavábamos, y traíamos nuestras cargas de agua y leña. Sus casas y mantenimientos son como las de los pasados, aunque tienen muy mayor hambre, porque no alcanzan maíz ni bellotas ni nueces. (...) De ocho meses que con ellos estuvimos, los seis padecimos mucha hambre, que tampoco alcanzan pescado ${ }^{35}$.

En otra ocasión:

nos partimos todos juntos con los indios, que iban a comer una frutilla de unos árboles, de que se mantienen diez o doce días, entretanto que las tunas vienen (...) Con éstos padecimos más hambre que con los otros, porque en todo el día no comíamos más de dos puños de aquella fruta, la cual estaba verde; tenía tanta leche, que nos quemaba las bocas; y con tener falta de agua, daba mucha sed a quien la comía ${ }^{36}$.

Incluso tuvieron que remediar su necesidad comiendo cueros o carne cruda:

Otras veces me mandaban raer cueros y ablandarlos. Y la mayor prosperidad en que yo allí me vi era el día que me daban a raer alguno, porque yo lo raía mucho y comía de aquellas raeduras, y aquello me bastaba para dos o tres días.

\footnotetext{
33 Ibidem. Cap. XVII. Cómo vinieron los indios y trajeron a Andrés Dorantes y a Castillo y a Estebanico.

34 Ibidem. Cap. XIX. De cómo nos apartaron los indios.

35 Ibidem. Cap. XXII. Cómo otro día nos trajeron otros enfermos.

36 Ibidem.
} 
También nos aconteció con estos y con los que atrás hemos dejado, darnos un pedazo de carne y comérnoslo así crudo, porque si lo pusiéramos a asar, el primer indio que llegaba se lo llevaba y comía ${ }^{37}$.

También comieron perro, un animal que normalmente hubieran rechazado como alimento: "Y como la hambre fuese tanta, nosotros comprámosles dos perros y a trueco de ellos les dimos unas redes y otras cosas, y un cuero con que yo me cubría" 38 . "Después que comimos los perros, pareciéndonos que teníamos algún esfuerzo para poder ir adelante..." 39

La expedición se había convertido en una odisea, años y años vagando por desiertos de hambre, en busca de un paraíso que se les escapaba continuamente. Un laberinto del que tampoco se podía salir para regresar a los lugares donde se hallaban los establecimientos españoles. Llegó un momento en que identificaron su destino con el maíz: "Pasados dos días que allí estuvimos, determinamos de ir a buscar el maíz..."40. Buscaban un paraíso en que todos los alimentos más preciosos se hallaban a disposición de todos, pero debían conformarse con el maíz. La comida que compartían con los indios era muy diversa, según los lugares:

...dieron a Dorantes más de seiscientos corazones de venados, abiertos, de que ellos tienen siempre mucha abundancia para su mantenimiento, (...) porque la costa no tiene maíz, y comen polvo de bledo y de paja y de pescado que toman en la mar con balsas. (...) Creemos que cerca de la costa, (...) hay más de mil leguas de tierra poblada, y tienen mucho mantenimiento, porque siembran tres veces en el año frísoles y maíz. Hay tres maneras de venados: los de la una de ellas son tamaños como novillos de Castilla ${ }^{41}$.

En su itinerario todavía les quedaba mucha hambre por pasar y contemplar:

Anduvimos mucha tierra, y toda hallamos despoblada, porque los moradores de ella andaban huyendo por las sierras, sin osar tener casas ni labrar, por miedo de los cristianos. Fue cosa de que tuvimos muy gran lástima, viendo la tierra muy fértil, y muy hermosa y muy llena de aguas y de ríos, y ver los lugares despoblados y quemados, y la gente tan flaca y enferma, huida y escondida toda. Y como no sembraban, con tanta hambre, se mantenían con cortezas de árboles y raíces. De esta hambre a nosotros alcanzaba parte en todo este camino, porque mal nos podían ellos proveer estando tan desventurados, que parecía que se querían morir. (...) Desde allí hacia el mediodía de la tierra, que es despoblada hasta la mar del Norte, es muy desastrosa y pobre, donde pasamos grande e increíble hambre ${ }^{42}$.

A medida que pasaron los años y a medida que el camino no llevaba a ninguna parte y desde luego no llevaba a la tierra de Jauja, tierra de abundancia en que la gran

\footnotetext{
37 Ibidem.

38 Ibidem.

39 Ibidem. Cap. XXIII. Cómo nos partimos después de haber comido los perros.

40 Ibidem. Cap. XXXI. De cómo seguimos el camino del maíz.

41 Ibidem. Cap. XXXII. De cómo nos dieron los corazones de los venados.

42 Ibidem.
} 
cantidad de manjares no solo ponía a salvo del hambre, sino que aseguraba la hartura y el deleite, Alvar Núñez Cabeza de Vaca dejó de buscar el paraíso en la tierra y comenzó a situarlo en el más allá. Incluso en clave religiosa, cuando el paraíso terrenal se convertía en paraíso celestial, soñaban con un cielo más material que espiritual, un cielo sin hambre, ni frío, ni sed:

Y el Melchor Díaz dijo a la lengua que de nuestra parte les hablase a aquellos indios, y les dijese como venía de parte de Dios, que está en el cielo, y que habíamos andado por el mundo muchos años, diciendo a toda la gente que habíamos hallado que creyesen en Dios y lo sirviesen, porque era Señor de todas cuantas cosas había en el mundo, y que él daba galardón y pagaba a los buenos, y pena perpetua de fuego a los malos; y que cuando los buenos morían, los llevaba al cielo, donde nunca nadie moría, ni tenían hambre, ni frío, ni sed, ni otra necesidad ninguna, sino la mayor gloria que se podría pensar" ${ }^{43}$

\section{PARAÍSOS DE ABUNDANCIA}

Desde el descubrimiento, el Viejo Mundo proyectó en el Nuevo Mundo muchos de sus sueños y deseos. Si Colón estaba convencido de haber hallado el Paraíso, otros muchos lo buscarían bajo nombres diversos, El Dorado, la Fuente de la eterna juventud... A pesar de los fracasos y de las decepciones, el sueño no desapareció. El paraíso se hallaba para muchos en el Perú. Jauja es la capital de la provincia del mismo nombre ubicada en el Departamento de Junín, en Perú. La palabra "jauja” puede ser la castellanización de "xauxa", "huacca" "sausa" o el quechua "hauca" que significa 'descansado, holgado'. El cambio esencial es que la tierra de Jauja, la tierra de Cucaña, adopta el nombre de un lugar real.

Grandes elogios le dedicaba Francisco de Jerez en su Verdadera relación de la conquista del Perú y provincia de Cuzco, llamada Nueva Castilla (Sevilla, 1534). Cieza de León narra, en Descubrimiento y conquista del Perú, cómo Pizarro estableció en Jauja la primera capital del Perú y el papel decisivo que jugó en la conquista del imperio Inca. En 1553 escribe en su Crónica del Perú, "Capítulo LXXXIV. Que trata del valle de Jauja y de los naturales dél, y cuán gran cosa fue en los tiempos pasados": "De Tamara, yendo por el real camino de los incas, se llega al grande y hermoso valle de Jauja, que fue una de las principales cosas que hubo en Perú" ${ }^{44}$. El Inca Garcilaso de la Vega comentaba sobre Jauja: "hermosísima provincia que tenía más de treinta mil vecinos..." ${ }^{45}$. Buscaban oro y plata, pero los españoles encontraron en América un tesoro mayor. Alimentos nuevos, maravillosos, maíz, patatas, cacao, judías, tomates, pimientos y pimentón, piñas, batatas, pavos... Productos llevados a tierras americanas que prosperaron de modo que parecía sorprendente, como sucedió con la caña de azúcar, los plátanos o el café. El gran intercambio de alimentos entre

43 Ibidem. Cap. XXXV. De cómo el alcalde mayor nos recibió bien la noche que llegamos.

44 CIEZA DE LEÓN, P.: Crónica del Perú, Barcelona, Red-Ediciones, 2012, pp. 222-224.

45 VEGA, EL INCA G. DE LA: Comentarios reales que tratan del origen de los Incas, Barcelona, RedEdiciones, 2012, Libro VI, Capítulo X, p. 36. 
el Viejo y el Nuevo Mundo, después extendidos a África y Asia, revolucionó la alimentación humana a escala planetaria, nada podría ser más similar a la tierra de Jauja. El mito parecía haberse hecho realidad.

El Dorado gastronómico americano se buscó en muchos lugares. Baltasar Gracián, en El Criticón situó en Brasil la tierra de promisión alimenticia, definiéndolo como "un paraíso confitado":

Y como cuando tú [la diosa Fortuna] comienzas a perseguir a unos y a favorecer a otros, no paras hasta que apuras, has llegado a verificar con ellos [los españoles] los que antes se tenían por entes de quimera, haciendo plásticos los mismos imposibles, como son ríos de plata, montes de oro, golfos de perlas, bosques de aromas, islas de ámbares; y sobre todo, los has hecho señores de aquella verdadera Cucaña donde los ríos son de miel, los peñascos de azúcar, los terrones de bizcochos: y con tantos y tan sabrosos dulces, dicen que es el Brasil un paraíso confitado ${ }^{46}$

A los ojos de los europeos América se convirtió rápidamente en un mundo ideal, en el que no faltaban perfiles de utopía alimentaria. Como recoge la literatura de la época, el Nuevo Mundo se identificaba con la Tierra de Jauja. Lope de Rueda en uno de sus pasos, precisamente titulado La tierra de Jauja (1547), se burlaba de los sueños de los españoles hambrientos: dos labradores entretienen al simple de Mendrugo con la descripción de unos lugares del nuevo continente en donde corren ríos de leche y de miel, las fuentes manan vino y manteca y suceden otro sinfín de prodigios naturales y todo ello de balde. Ideas parecidas aparecen en otras obras como en El talego-niño del entremesista Luis Quiñones de Benavente, en El culto sevillano de Juan de Robles, en el Guzmán de Alfarache de Mateo Alemán o en el Romance de la isla de Jauja, que prueba la difusión popular que alcanzó el mito de las riquezas inagotables de las Indias ${ }^{47}$.

\section{LA TIERRA DE JAUJA}

La tierra de Jauja, como Cucaña, era un país mágico con el cual se soñaba en la edad Media y en la edad Moderna. En esta tierra fantástica no era necesario trabajar y el alimento era abundante. Los ríos eran de vino, de leche y de miel, había montañas de queso y de los árboles pendían lechones ya asados, con una faca en el lomo, listos para ser prontamente degustados. El mito surgió en una sociedad estamental injusta y oprimida, no es de extrañar que la fantasía popular pusiera su esperanza en la existencia de lugares imaginarios donde no había sufrimiento y donde los placeres carnales eran ilimitados. En esta época, las utopías colectivas basadas en las promesas de un mundo mejor presentan una enorme difusión y variedad: así, en España el lugar se denominó Jauja o Cucaña, en Alemania Schlaraffenland o Venusberg (monte de Venus), el Paese della

46 GRACIÁN, B.: El Criticón, Madrid, Espasa Calpe, 1971, Crisi Tercera, p. 67.

47 FERNÁNDEZ NIETO, M.: "América en la literatura española" en La huella de América en España, Valencia, Generalitat valenciana, 1993, p. 424. MORINIGO, M. A.: América en el teatro de Lope de Vega, Buenos Aires, Instituto de Filología, 1946. FRANCO, Á.: El tema de América en los autores del Siglo de Oro, Madrid, 1954. PEDRO, V. de: América en las letras españolas del Siglo de Oro, Buenos Aires, Edit. Sudamericana, 1954. 
cuccagna en Italia, en Francia el Pays de Cocagne. Esta palabra quedó definitivamente incorporada al castellano: la cucaña es un palo largo, untado de grasa, al cual hay que trepar o andar en equilibrio para coger el premio, normalmente un manjar o un gallo colgado en la punta. La misma utopía también está presente en el Paraíso de Eldorado, que creyera vislumbrar Álvar Núñez Cabeza de Vaca en tierras de Nuevo México, y que dio lugar al fracasado proyecto de Lope de Aguirre, o en la ínsula Barataria del Quijote.

No sólo se ocupaba la literatura, también la pintura evocaba ese sueño de abundancia. Una buena representación de esta tierra mítica se halla en el cuadro realizado por Pieter Brueghel el Viejo, El país de Jauja, (Het Luilekkerland), de 1567, (Alte Pinakothek, Múnich). El país de Jauja era uno de los temas preferidos de Brueghel, que siguió a El Bosco en la representación de la locura de los hombres, como ya hizo en sus Proverbios flamencos. El cuadro representa, en torno al árbol de la buena mesa, a tres hombres gordos, borrachos, tumbados, representando a tres clases sociales distintas. Un caballero, junto al que se encuentran sus armas, dormita en apacible somnolencia, signo de ignorancia; un campesino, grueso como un tonel, yace de espaldas sobre su mayal, utensilio agrícola usado para golpear la parva y más de una vez convertido en arma; y un burgués letrado, tumbado sobre un abrigo de pieles, con las piernas abiertas y la Biblia cerrada a su lado, levanta la vista con expresión perdida... Se transmite así el mensaje de que los vicios afectan a todos, independientemente de su condición. Personajes distintos, pero los tres unidos por la indolencia, la saciedad, la pereza y la gula.

En la pintura de Brueghel, un personaje con yelmo y coraza, contempla la tierra de Jauja desde la salida de una especie de túnel, adornado de tartas y pasteles. Cuando el afortunado mortal consigue llegar a la tierra prometida, comienza la anhelada existencia del ocio y la glotonería. A sus ojos de ofrece el espectáculo de un cactus formado por tortas de pan, largas salchichas enrolladas, que forman una valla, un cochinillo asado que se pasea con el cuchillo clavado en el lomo, dispuesto a ser trinchado, y un ganso cebado, servido en una bandeja. Abajo, en el centro de la imagen, deambula un extraño huevo pasado por agua, con patas, que se ha interpretado como una referencia a Satanás, mientras que el cuchillo que tiene dentro sería un símbolo fálico. Junto al caballero embriagado, un vaso gotea los últimos restos del licor que ha bebido. Visiones que constituyen el símbolo de lo irracional, de las pasiones ciegas, de los sueños de abundancia y glotonería.

En la España Moderna todavía se conservaba el recuerdo de la leyenda medieval de Jauja o de Cucaña. Lope de Rueda, que fue uno de los primeros actores profesionales españoles, fue, además un dramaturgo de gran versatilidad que escribió comedias, farsas y pasos o entremeses. Los Pasos se publicaron en Valencia en dos volúmenes: El deleitoso y Registro de representantes. Uno de los pasos que escribió fue "La tierra de Jauja", un episodio humorístico en el que dos pícaros hambrientos, Honzigera y Panarizo, le roban la comida al ingenuo Mendrugo, al que entretienen contándole el cuento de la tierra de Jauja ${ }^{48}$.

48 RUEDA, L. de: Pasos, ed. José Luis Canet Vallés, Madrid, Castalia, 1992. GIMBER, A.: "Sobre el origen del quinto paso del Deleytoso de Lope de Rueda", Revista de Filología Española, vol. LXXV, n. ${ }^{\circ} 3 / 4$ (1995), pp. 281-286. 
El punto de partida es siempre el hambre:

HONZIGERA: ¡Ea!, no te dejes amilanar, hermano Panarizo. Di, ¿tienes hambre? PANARIZO: ¿Que si tengo hambre? Un pollo me comería con plumas y todo.

Y lo que buscan para comer no son leyendas, porque las leyendas no llenan el estómago. Sueñan con pollos, porque entonces la volatería era la carne más apreciada y deseada. Pero tienen que conformarse con lo que encuentran, que son albóndigas, uno de los platos más comunes y populares de la época:

MENDRUGO: Ah, ¿esto? No es ningún recipiente; es una cazuela. Llevo unas albóndigas para la Tomasa, que se pirra por ellas. Las he hecho yo mismo, con carne de la mejor, huevos y especias, todo bien rebozado con harina blanca.

HONZIGERA: Estarán buenas.

MENDRUGO: Como para chuparse los dedos.

Frente a la realidad del hambre, frente a la realidad de los pollos y de las albóndigas, el sueño es la tierra de Jauja, donde todo es abundante, fácil y delicioso. Ríos de leche y miel, fuentes de mantequillas y requesones, árboles de tocino, hojas de pan fino, frutas que son buñuelos, calles empedradas con yemas de huevo y lonjas de tocino, asadas y fritas, asadores larguísimos llenos de gallinas, capones, perdices, cazuelas con queso y huevos, cajas de confituras, mazapanes, merengues, arroz con leche, natillas, vino dulce... Es una lista perfecta de los alimentos más deseados de la época, significativamente no hay verduras ni legumbres, que eran, en cambio, los alimentos consumidos mayoritariamente y cotidianamente por las clases populares. Para las gentes comunes y corrientes de la España moderna los alimentos de Jauja eran los ingredientes maravillosos de su imaginario de la abundancia feliz, manjares que se ofrecen tentadores: "Cómeme, cómeme".

HONZIGERA: Mira: en la tierra de Jauja hay un río de miel y otro de leche, y entre río y río hay una fuente de mantequilla y requesones, y caen en el río de la miel, que no parece sino que están diciendo: «cómeme, cómeme». (...)

PANARIZO: Mira: en la tierra de Jauja hay unos árboles que son de tocino.

MENDRUGO: ¡Oh, benditos árboles! Dios los bendiga, amén.

PANARIZO: Y las hojas son de pan fino, y los frutos de estos árboles son de buñuelos, y caen en el río de la miel, y ellos mismos están diciendo: «máscame, máscame». (Mendrugo se pone a mascar, como si los tuviera en la boca.) (...)

HONZIGERA: Mira: en la tierra de Jauja las calles están empedradas con yemas de huevo, y entre yema y yema, un pastel con lonjas de tocino.

MENDRUGO: ¿Asadas?

HONZIGERA: Asadas, fritas y de todo, de modo que ellas mismas están diciendo: «trágame, trágame».

MENDRUGO: Ya parece que las trago. (...)

PANARIZO: Mira: en la tierra de Jauja hay unos asadores de trescientos pasos de largo, con muchas gallinas, capones, perdices... 
MENDRUGO: (Relamiéndose.) ¡Huuum! ¡Con lo que a mí me gustan!

PANARIZO: Y junto a cada ave un cuchillo, de modo que no es necesario más que cortar, pues ellos mismo lo dicen: «engúlleme, engúlleme».

MENDRUGO: (Pasmado.) ¡Cómo! ¿Las aves hablan?

HONZIGERA: Óyeme.

MENDRUGO: Ya le oigo, señor. Me estaría todo el día oyendo cosas de comer.

HONZIGERA: Mira: en la tierra de Jauja hay muchas cajas de confituras, mazapanes, merengues, arroz con leche, natillas...

MENDRUGO: Por favor, señor, más despacio, que así no puedo gustarlo como quisiera.

HONZIGERA: Y hay unos barriles de vino dulce junto a las confituras, y unas y otras están diciendo: «cómeme, bébeme, cómeme, bébeme...»

MENDRUGO: ¡Ay, ya parece que las como y las bebo!

PANARIZO: Mira: en la tierra de Jauja hay muchas cazuelas con huevos y queso.

Del paso de Lope de Rueda existen versiones diversas. En otra versión se introducen ligeras variantes. Las hojas de los árboles no son de pan fino, sino de hojuelas, un dulce de masa frita con miel, muy apreciado en aquellos tiempos y que se convirtió en una frase, "miel sobre hojuelas", que expresa algo bueno sobrepuesto a otra cosa buena. Entre los dulces se incluyen además el calabazate, el diacitrón, los confites y las grageas, todos igualmente muy bien valorados por los gustos del tiempo. Y las cazuelas son en este caso de arroz, huevos y queso. Algunas ligeras variantes, pero siempre orientadas en la misma dirección.

MENDRUGO: ¡Oh, qué buena tierra! Cuénteme las maravillas de esa tierra, por vida suya. [...]

HONZIGERA: Mira: en la tierra de Jauja hay un río de miel y junto a él otro de leche, y entre río y río hay una fuente de mantequillas encadenada de requesones y caen en aquel río de la miel, que no paresce sino que están diciendo: «cómeme, cómeme». [...] PANARIZO: Mira: en la tierra de Jauja hay unos árboles que los troncos son de tocino. MENDRUGO: ¡Oh benditos árboles! Dios os bendiga, amén.

PANARIZO: Y las hojas son hojuelas, y el fruto de estos árboles son buñuelos, y caen en aquel río de la miel, que ellos mismos están diciendo: «máscame, máscame».

HONZIGERA: Vuélvete acá.

MENDRUGO: Ya me vuelvo. [...]

HONZIGERA: Mira: en la tierra de Jauja hay muchas cajas de confitura, mucho calabazate, mucho diacitrón, muchos mazapanes, muchos confites.

MENDRUGO: Dígalo más pausado, señor, eso.

HONZIGERA: Hay ragea y unas limetas de vino que él mismo se está diciendo: «bébeme, cómeme; bébeme, cómeme».

PANARIZO: Ten cuenta. 
MENDRUGO: Harta cuenta me tengo yo, señor, que me paresce que engullo y bebo. PANARIZO: Mira: en la tierra de Jauja hay muchas cazuelas con arroz y huevos y queso.

Muy clara la extrema tensión entre la realidad y el ideal. La utopía de comer mucho y bien frente a la cotidiana presencia del hambre. La resolución del conflicto es benévola para los hambrientos. Aunque los pícaros le han robado a Mendrugo la cazuela de las albóndigas, que le llevaba a su mujer que estaba en la cárcel, Mendrugo acaba por comprenderlos, les perdona, porque el hambre es razón poderosa, y se culpa por dejarse embaucar con sueños de abundancia.

MENDRUGO: ¿Cómo ésta que yo traigo? (Mira la cazuela) ¡Anda, si está vacía! (Honziguera y Panarizo hacen mutis corriendo. Mendrugo, dando voces tras ellos) ¡Ladrones! ¡Ladrones! (Se detiene de pronto y mira la cazuela tristemente) Me han dejado sin un buñuelo. ¡Pobre de mí! ¿Y qué hago yo ahora? (Pausa) Pobrecillos, a lo mejor es que tenían hambre... ¡Que Dios les perdone el daño que me han hecho! La culpa la he tenido yo, por creer que hay tierras en donde se puede vivir sin trabajar. Esto me servirá de lección (Vase tristemente por donde vino).

\section{ISLAS PRODIGIOSAS}

Además del paso de Lope de Rueda, existen romances sobre la Tierra de Jauja, identificada con una isla, que sitúan en lugares indefinidos del océano. Muy interesante es un pliego suelto titulado: "Breve relación y curiosa carta que da cuenta de una prodigiosa isla que se ha descubierto junto al reino de Matricados, llamada Isla de Jauja. Refiérese con el aparato, ostentación y grandeza que se vive en ella, como la declara la gustosa copla, que es la siguiente" 49 .

Desde el punto de vista del imaginario de la abundancia, lo que aporta este romance es la gran variedad de productos y platos que ofrece, lo que añade calidades a la mera cantidad y entre los que se encuentran algunos de los más famosos y apreciados de la época, como el manjar blanco. Se dibuja una apasionante geografía gastronómica. El romance da una larga lista de platos horneados, molletes, pan, bizcochos, chuletas, empanadas, pastelones, lechones, tortadas, cazuelas, tanto de carne como de pescado:

Primeramente hay en ella, a trechos proporcionados,

Treinta mil hornos, y todos tienen, sin costar un cuarto,

Con abundancia molletes, pan de aceite azucarado,

Vizcochos de mil maneras, chullas de tocino magro,

Empanadas excelentes de pichones y gazpachos,

De pollos y de conejos, de faisanes y de pavos,

49 DURÁN, A.: Romancero general o Colección de romances castellanos anteriores al siglo XVIII / recogidos, ordenados, clasificados y anotados por Agustín Durán, Madrid, D. L. Amarita, 1829, tomo II, nº 1347. 
De lampreas, de salmones, de atunes, truchas y barbos,

De sabogas y besugos, y de otros muchos pescados;

Pastelones de ternera, lechoncillos bien tostados,

Tortradas de varios dulces, y de sazones agrios;

Cazuelas de codornices, de arroz, tórtolas y gansos

Y de pícaros bobos sabrosos y extraordinarios.

Seguía después una lista de bebidas, vinos, tintos y blancos, especiados, refrescos, vinagres, aguardientes, agua:

Hay un mar de vino griego, otro de San Martín, blanco,

Dos ríos de Malvasía, de vino moscatel cuatro.

De hipocrases tres arroyos, de limonada diez charcos,

De agua de limón y guindas, canela y anís, seis lagos;

De vinagre blanco y tinto diez balsas en breve espacio,

De aguardiente treinta pozos, los más de ellos anisados;

De agua dulce, clara y fresca, doce mil fuentes, que es pasmo

Lo artificioso de todas, lo primoroso y lo vario;

No podían faltar los postres, los dulces y los salados. Entre los dulces se mencionan confituras, pasteles, natas, entre los que se hallaban algunos de los más tradicionales y valorados en aquellos tiempos como el manjar blanco. También los postres salados, como quesos, aceitunas y alcaparrones, que entonces se tomaban al final de las comidas:

De queso una gran montaña, de mantecadas un campo,

De manjar blanco un dehesa y de cuajada un barranco,

Un valle de mermeladas, de mazapanes dos llanos.

De canalones dos montes, y de acitrón dos collados.

Hay de miel un largo río, guarnecido y margenado.

De arboledas, cuyos frutos son pellas de manjar blanco;

Hay hojaldres muy sabrosos, buñuelos almibarados,

Mantequillas, requesones y pepinos confitados.

Hay treinta acequias de aceite, y un dilatado peñasco,

La mitad de queso fresco, y la otra mitad salado.

Hay diez y siete lagunas continuamente manando

Aceitunas como huevos, y alcaparrones tamaños;

Hay de leche un ancho río, en muchas partes helado

otro de natas y azúcar, a los golosos brindando.

También se citan diversas frutas frescas, que de manera extraordinaria se hallaban en sazón todo el año:

Hay una hermosa arboleda, que tiene por todo el año, Peras, membrillos, camuesas, melocotones, duraznos, Manzanas, granadas, higos, todo bueno y sazonado.

Hay campos que dan melones, ya blancos, ya colorados, Ya chinos, ya moscateles, ya escritos, ya borrados. 
Finalmente se habla del ganado y de los animales de caza, incluyendo el destinado al consumo alimentario:

Hay un espacioso bosque adonde nacen caballos

Andantes y corredores, ensillados y enfrenados,

Potros, yeguas, mulas, vacas, carneros, cabritos, gamos,

Corzos, cabras y terneras, jabalíes y venados.

Más adelante se completa el panorama con una montaña de nieve, que además de equilibrar el clima, resulta una interesante referencia de la pasión existente en la época por las bebidas refrescadas con nieve o hielo. Y con un maravilloso huerto, que combina los metales preciosos, oro y plata, con la volatería, perdices, gallipavos y capones, a los que se añaden también los conejos, todos ellos productos de gran prestigio en la alimentación de la edad moderna:

De nieve hay una gran montaña, de virtud prodigio raro,

Que calienta en el invierno y refresca en el verano.

Hay en cada casa un huerto de oro y plata fabricado,

Que es prodigio lo que abunda de riquezas y regalos.

A las cuatro esquinas de él hay cuatro cipreses altos:

El primero de perdices, el segundo gallipavos.

El tercero cría conejos, y capones cría el cuarto.

Al pié de cada ciprés hay un estanque cuajado,

Cuál de doblones de a ocho, cuál de doblones de a cuatro.

El romance acababa animando a todo el mundo, caballeros, hidalgos y miserables, a partir en busca de aquella tierra maravillosa:

Animo, pues, caballeros, ánimo pobres hidalgos;

Miserables, buenas nuevas, albricias, todo cuitado,

Que el que quiera partirse, a ver este nuevo pasmo,

Diez navíos salen juntos de la Coruña este año.

La tradición de la Isla de Jauja continuó viva en la España del siglo XVII. En Barcelona, el año 1660, se publicó una nueva versión: "El venturoso descubrimiento de la nueva y fértil tierra de Xauxa, por otro nombre llamada Madrona. Descubierta por el dichoso y bien afortunado Capitán llamado Longares de Sentlom y de Gorgas." En "El venturoso descubrimiento de la nueva y fértil tierra de Jauja" se cuenta cómo "el capitán Longares / de Sentlom y de Gorgas / con un bergantín no más / [...] una isla ha descubierto / [...] llamada Jauja, o Madrona". Se hacía una detallada la descripción de las maravillas del lugar: desorejan al que trabaja, el Descuido y la Locura son guardas reales, "el oro tienen por lodo", "el que ronca más doblado / es tenido por honrado", hay "hoyos de do salen gallos" y peces que se dejan pescar fácilmente. Al final hay una advertencia dirigida a alquimistas, quiromantes, trampistas, holgazanes, cicateros, charlatanes, adivinos, fanfarrones, ladrones: "y vosotros, engorrados, / comiendo ajeno sudor, / los que buscáis nueva flor / nunca oída, / poseyendo en esta 
vida / oficios de poca estofa. / Por vivir en la gallofa, / ¿qué esperáis / que de España no vaciáis, / enemigos de la hacienda, / que en la Jauja sin enmienda / os darán cuanto pidáis?" 50 . La conclusión era muy clara, aunque el sueño de Jauja continuaba, era preciso despertar.

\section{EL TIEMPO DE MARICASTAÑA, LA ISLA DE CHACONA, LA TIERRA DE PIPIRIPAO}

Tiempos y lugares míticos existieron varios y en muchos de ellos también se proyectó el imaginario de la abundancia. Ejemplo de un tiempo perdido y añorado donde todo era extraordinario, evocación a su manera de la anhelada Edad de Oro, era el relato manuscrito del siglo XVI, titulado: "Vida y tiempo de Maricastaña" En ese tiempo remoto existía una especie de paraíso perdido en el que siempre era verano, en el que el campo producía manjares, había grutas de azúcar y fuentes de leche, la retama daba higos, la encina daba miel, los ríos eran de vino, de las variedades San Martín y Rivadavia, y en lugar de peces en ellos se podían pescar salchichones, los dulces y los quesos formaban montañas, había valles de manjar blanco, perdices que volaban asadas y con solo desearlas cualquiera las podía coger y comérselas, en los prados nacían tortas y las vallas eran de turrón de Alicante, llovían hojaldres, en la ciudad las calles estaban empedradas con huevos fritos y las casas tenían paredes de mazapán. La comida abundaba por todas partes, los capones asados caminaban por las calles y el jamón conversaba con las gentes, las gallinas eran gordas "cual no se vio en tierra de Bavia", en las escuelas se enseñaba a hacer frutas de sartén. La comida tenía enorme prestigio y se consideraba que el hombre más honrado era el que más comía ${ }^{51}$.

Otro buen ejemplo de un lugar maravilloso es "La isla Chacona", romance publicado en Primavera y flor de romances, en 1621. Es una isla maravillosa, fértil y abundante, donde miles de mesas ofrecen manjares para todos:

Esta tierra, amigos míos, / es la isla de Chacona, / por otro nombre Cucaña, / que de ambos modos se nombra. / Los aires de este país / son vientecillos que soplan, / por regalar el olfato, / la fragancia de las rosas; / cristales frescos las aguas / con muchas fuentes de aloja, / y a cada paso entre nieve / de vino mil cantimploras. / De la otra parte del río / hay árboles que sus hojas / dan panecillos de leche, / y por frutas llevan roscas. / Los huesos de aquestas frutas / son mantequillas y lonjas, / que dentro en los panes nacen / con que se pringuen y coman. Hay un árbol que es tan grande / que debajo de su sombra / caben cuarenta mil mesas, / y en cada veinte personas. / La frutas de este son pavos, / perdices, liebres, palomas, / carneros y francolines, / gallinas, capones, pollas. / Todos se nacen asados / y guisados, de tal forma / que parece que da el árbol / también cazuelas y ollas. / Y en sentándose en la mesa / solo con que un hombre ponga / la vista en lo que desea, / se cae a pedir de boca.

\footnotetext{
50 El venturoso descubrimiento de la nueva y fértil tierra de Xauxa, por otro nombre llamada Madrona, Barcelona, en la imprenta de Martín Salabert, 1660, 4 pp.

51 MADROÑAL DURÁN, A.: "La tierra de Jauja en entremeses barrocos" en REVERTE BERNAL, C. y REYES PENA, M. de los (eds.): II Congreso Iberoamericano de Teatro: América y el teatro español..., Volumen 2, pp. 435-447.
} 
La conclusión final es una invitación a irse todos a esa isla fabulosa: "Y ésta sí que era vita bona: / vámonos todos a Chacona" 52 .

Los lugares maravillosos eran muchos y muy variados. Otro caso era la tierra de Pipiripao, que menciona Cristóbal Suárez de Figueroa en El Pasajero, un país mágico, "donde los ríos son de miel y los árboles producen tortadas" y al que todos están deseando ir:

Como ya plático, engaité a cuantos pude, con encaramarles mucho las cosas de aliende el mar. Asegurábales ser sólo sedas y brocados los que se gastaban en vestir; las comidas, siempre en forma de grandes banquetes, y todo como se finge pasa en la tierra del Pipíripao, donde los ríos son de miel y los árboles producen tortadas. Caían en la trampa como moscas... ${ }^{53}$

El lugar ha tenido el prestigio añadido de pasar al refranero, insistiendo en la idea de la maravilla que era vivir sin trabajar, pero vivir en la abundancia: "En la tierra del Pipiripao, donde no se conoce el trabajo, todos mueren de hartazgo". El Diccionario de la Real Academia da la siguiente definición de Pipiripao: "Convite espléndido y magnífico, especialmente el que forma parte de una serie de ellos que se van haciendo un día en una casa y otro en otra."

\section{PARAÍSOS PINTADOS}

La idea de paraíso tiene un origen común en diversos pueblos de la antigüedad y aparece tanto en la tradición semita como en la grecolatina. En el Génesis se describe como un lugar de belleza especial donde el hombre vivía en perfecta armonía con la naturaleza hasta su caída y posterior expulsión del mismo. De este modo se incorporó a la cultura occidental una idea de nostalgia y un deseo por recuperar ese paraje idílico perdido. Es a través de la pintura de paisaje donde los artistas podrán reflejar ese mito, esa realidad idealizada o ese ambiente bucólico y sereno desaparecido. Esta primera idea, tal y como aparece descrita en la Biblia, fue reflejada por Jan Brueghel el Viejo en El Jardín del Edén, donde el hombre convive en plena armonía con todos los seres de la Creación. La obra sigue la tradición bíblica, con los animales de la creación en primer plano y, al fondo, Adán y Eva. (Museo Thyssen-Bornemisza, Madrid).

El mismo tema será tratado en El Paraíso terrenal, de Brueghel "el Joven", copia de Bruegel "el Viejo", pintado hacia 1626. (Museo del Prado, Madrid). Como es habitual en Jan Brueghel el Joven, el modelo iconográfico para esta composición se encuentra en los paisajes de Adán y Eva en el Paraíso inventados por su padre, Jan Brueghel el Viejo. Sin embargo, al contrario que en esos paisajes del padre, a primera vista parece que aquí lo importante no es el relato bíblico ni los animales

52 DURÁN, A.: Romancero general o Colección de romances castellanos anteriores al siglo XVIII / recogidos, ordenados, clasificados y anotados por Agustín Durán, Madrid, D. L. Amarita, 1829, tomo II, p. 283.

53 SUÁREZ DE FIGUEROA, C.: El Pasajero, edición crítica y anotada de María Isabel López Bascuñana, Barcelona, Promociones y Publicaciones Universitarias. S. A., 1988. 
representados, sino el bosque, que está ejecutado con extrema minuciosidad. La obra está compuesta a base de una delicada armonía de verdes, amarillos y ocres con las vivas notas de color del plumaje de los papagayos como contrapunto. Gigantescos robles de espeso follaje dominan el paisaje, en el que se descubren variadas parejas de animales que pueblan este bosque y en el claro del fondo se descubre una diminuta pareja humana desnuda y de pie bajo un árbol. Las manzanas del gran árbol en el primer plano, permiten identificar a la pareja del fondo como Adán y Eva en el Paraíso, debajo del Árbol de la Vida antes de caer en el pecado original (Génesis 2). Es sorprendente la minuciosidad en la representación de los árboles, así como de las hierbas y las plantas. De esta composición se conserva una réplica original (Berlín, Gemäldegalerie), así como diversas copias de seguidores que hablan del éxito de esta composición.

Del tema existen numerosas versiones. Muy curioso resulta que en muchos de los cuadros entre los animales del Jardín del Edén figuran representaciones de la fauna del Nuevo Mundo, sobre todo vistosos pájaros como los papagayos, pero también aparecen hermosos pavos, el animal de procedencia americana que más rápidamente se incorporó a las mesas españolas y europeas y que mayor importancia tiene en la alimentación ${ }^{54}$.

Muy significativos son los cuadros sobre el mito de la abundancia, por ejemplo el cuadro titulado precisamente La Abundancia, de Jan Brueghel el Joven, pintado hacia 1625. (Museo del Prado). Centra la composición una figura con seis pechos que representa la Fertilidad. Porta un cuerno de la Abundancia y le acompañan cuatro niños, tal vez símbolo de las estaciones del año. En torno a ella se despliegan los recursos que proporciona la Naturaleza, tanto del mundo vegetal, como muestran las numerosas especies de árboles, flores y frutos, como del mundo animal, a través de diversos especímenes entre los que se cuentan mamíferos domésticos y salvajes, ejemplares exóticos, reptiles, insectos, peces y crustáceos, todos ellos tratados con un detallismo preciosista ${ }^{55}$. Este tipo de representación alegórica de la Abundancia o de la Fecundidad fue muy célebre entre la pintura de gabinete de la época. Artistas como Rubens, Jan Brueghel el Viejo, Hendrick de Clerck y Hendrick van Balen, entre otros, también la practicaron.

Otra versión del tema es el cuadro de Pedro Pablo Rubens y Frans Snyders, titulado Ninfas con el cuerno de la abundancia (Museo del Prado), pintado hacia 1620. Se inspira en textos clásicos y muestra a tres hermosas y sensuales jóvenes, que aluden a la fecundidad de la tierra. Una de las jóvenes se ha identificado con Ceres, diosa de la fecundidad y las cosechas. La cornucopia es símbolo de abundancia. El tema de la Naturaleza como constante generadora de vida es frecuente en la pintura de Rubens, que a menudo lo asocia a la sexualidad. En este caso, al situar la cornucopia entre las piernas de una de las ninfas, Rubens seguramente pretende utilizar el simbolismo se-

\footnotetext{
54 AMADO DOBLAS, M. I.: "El pavo en el imaginario de la opulencia indiana, visto desde la literatura del Siglo de Oro", Isla de Arriarán, XXVI, diciembre (2005), pp. 263-286.

55 La Belleza Cautiva. Pequeños tesoros del Museo del Prado, Museo Nacional del Prado, Obra Social la Caixa, 2014, p. 132.
} 
xual para enfatizar la idea de la abundancia y fecundidad de la Naturaleza. Las frutas $\mathrm{y}$ animales fueron pintados por Frans Snyders ${ }^{56}$.

Perspectiva distinta, pero igualmente interesante, del mito de la abundancia lo proporcionan las imágenes del gusto, que se ofrecen en las series de cuadros de los sentidos, tan típicos del Barroco. Ejemplo destacado es el cuadro titulado El Gusto, de Pedro Pablo Rubens y Jan Brueghel el Viejo, un cuadro de gabinete perteneciente a la serie de Los Sentidos creada para los archiduques Alberto e Isabel Clara Eugenia en 1618. La serie de Los Sentidos es uno de los mayores logros estéticos de la colaboración artística entre Rubens, que realizó las figuras alegóricas de cada uno de los sentidos, y Jan Brueghel, que representó los exuberantes escenarios cortesanos. La opulencia del bodegón que se ve en el primer plano de El Gusto y la frondosidad del paisaje exterior, aluden a la abundancia de los Países Bajos y al lujo de la Corte de los Archiduques, pero aluden también indirectamente a ese mito de la abundancia generosa e inacabable, ofrecida a todos, en este caso al menos a sus ojos deslumbrados y golosos ${ }^{57}$.

Mitos de abundancia, imaginados, deseados, buscados, creados, disfrutados de formas distintas por gentes diversas, cada uno a su manera, según las clases sociales, las culturas, los gustos, los lugares y los tiempos. Un solo sueño, soñado de mil maneras, el mismo placer gozado de mil modos, desde el infierno del hambre al paraíso de la abundancia.

56 PÉREZ PRECIADO, J. J. y VERGARA, A.: Rubens. Guía de exposición, Madrid, Museo Nacional del Prado, 2010.

57 Ibidem, p. 14. 